\title{
Literature Review of the Cooperative Learning Strategy - Student Team Achievement Division (STAD)
}

\author{
Hastings Chim Ho Yeung, ${ }^{1, *}$ \\ ${ }^{1}$ University of Bristol, UK \\ *Correspondence: University of Bristol, UK. E-mail: hastings.chim@bristol.ac.uk
}

Received: November 16, 2014 Accepted: January 14, 2015 Published: January 22, 2015

doi:10.5296/ije.v7i1.6629 URL: http://dx.doi.org/10.5296/ije.v7i1.6629

\begin{abstract}
The literature review will include the development of cooperative learning (CL) and in-depth review on one of its derived teaching strategies, Student Team Achievement Division (STAD). It will highlight the emergence of STAD, major issues, debates, and recent investigations regarding its effectiveness, achievability, and practicability. The conclusion of this literature review provides a participative action inquiry into possible interventions. The literature review is highly relevant to the suggested research interest for some of the theoretical and conceptual frameworks and methodologies are searched and based on the existing STAD practice and knowledge in these two decades. The areas include the longitudinal and latitudinal review of relevant conceptual framework and methods, which further refine the newly proposed research questions and enhance their workability and practicability.
\end{abstract}

Keywords: STAD, Cooperative Learning, Research Methodology 


\section{Introduction}

In this literature review we will include the development of cooperative learning (CL) and in-depth review on one of its derived teaching strategies, Student Team Achievement Division (STAD). Moreover, we will critically evaluate five pieces of researches in which it will highlight the emergence of STAD, major issues, debates, and recent investigations regarding STAD effectiveness, achievability, and practicability. The first one is from Ghazi (2001) which investigated students' enjoyment and reflection of STAD during an English lesson as Foreign Language (EFL) class in Lebanon. The study is unique because it examined the effect of gender and the students' achievement on the account of their STAD experiences. The perceptions from teachers are equally important so the second one selected is from the same researcher, Ghazi (2004), who further investigated the teachers' opinions on the STAD practice in Lebanon. Apart from the teachers and students, the contextual factors which influence the practice are also worth exploring. The third one is therefore from Khan \& Inamullah in Pakistan (2011) which looked into the difference of effectiveness of STAD between experiment and control groups and how various contextual factors influenced the implementation. The work from Van Wyk (2010) in University of South Africa, which attempted to enhance the existing STAD practice and look into how the achievement scores were related to the modified practice, is selected as the fourth piece of research since it adopted a comparatively different quantitative approach by cumulating the use of the questionnaires. The last one was from Gillies (2004) in Australia which adopted a triangulative method to investigate the difference of structured and unstructured STAD groups. Gillies work(2004) is significant for it adopted a more holistic and comprehensive data collection for better reliability. Currently there are no researches related to STAD implemented in Hong Kong, all those five researches are hence chosen from different countries so that the glimpse on the global practice can be reviewed in this literature review.

\section{Student Team Achievement Divisions (STAD)}

Student Team Achievement Divisions (STAD) was established based on the fulfillment of instructional pedagogy (Felder \& Bren, 2001; Ghaith, 2001). Four to five students will be assigned to various groups comprising certain levels of differentiation: competence, sex, race, and so on. In this case, teachers, as facilitators, would brief the students with concise yet precise instructions. Subsequently, students will read assigned material in the Expert Group before being reclassified into STAD groups to exchange their thoughts. After the discussion in the Expert Group, the students would then return to their STAD groups for information synthesis. They will have to justify others' opinions, peer evaluate their understanding, and summarize the concepts that each individual student contributed. An assessment will evaluate their grasp of the key ideas using presentations, quizzes, and applications. Their improvement will be measured through the scores accumulated. 


\section{Theory, Conceptual Framework, and Current Debates on STAD}

In the early 1900s, Kurt Koffka, a founder of the Gestalt School of Psychology, categorically proposed that group work is cohesive and vital, and that interdependence could vary among individuals and the interdependence among group members trigger changes from individuals to the whole group and vice versa (Johnson, Johnson \& Stanne, 2000). The bonding and interaction among group members effectively motivate students to accomplish the expected and compromised common goals (Johnson, Johnson, \& Stanne, 2000). Such conceptual framework has been categorized into five essential elements for cooperative learning (Slavin, 1980; Slavin, 1987; Cohen, Brody \& Sapon-Shevin, 2004): 1. positive interdependence; 2. face-to-face interaction; 3. individual and group responsibility; 4. social skills (leadership, decision-making, trust-building, communication, and conflict management skills); and, 5. group processing.

As one of the most prevalent CL strategies, STAD has become salient among various pedagogies for three major reasons. First, this strategy is cohesively embedded in various basic theories in psychology, political science, sociology, economics, anthropology, and the social sciences (Slavin, 1980; Slavin, 1987; Cohen, Brody \& Sapon-Shevin, 2004). Second, numerous studies have investigated and compared this instructional strategy with others. Most indicate that STAD is more prominent and advantageous in terms of generalization, breadth, and application (Armstrong \& Palmer, 1998; Ghaith, 2002). More importantly, most teachers, even the writer who is also a teacher, regard STAD as a highly applicable teaching method, handy and consistent with teaching philosophies and practices (Hertz-Lazarowitz, \& Miller, 1995). In summary, STAD is grounded on theory, research-driven, pragmatic, and highly compatible with existing practices.

Inevitably, STAD has received considerable criticism from students, such as that interdependence might have negative effects if participants are unable to find any link between participation and outcome (Johnson \& Johnson, 2009). For example, STAD will not have any effect if the participants feel they are detached and ignored during the activity. Second, if the competent groups outperform their peers, the attention received by the better groups may discourage other groups, who run the risk of being marginalized (Johnson, Johnson \& Skon, 1979). Third, the Cooperative Learning rationale requires teachers to assign students into different groups based on a various variables, such as their second language competence. Such individual difference might discomfort those students who have not yet mastered the second language, and thus, impede their collaboration with more capable students (Jacob, Rottenberg, Patrick \& Wheeler, 1996). Jolliffe. (2007) also points out the potential drawbacks STAD might bring teachers, such as its evolutional process, which might confuse practitioners. Teachers, in fact, constantly suffer from an inadequate understanding of the method. They may also receive criticism from more competent students who are slowed down by peers, while less capable students may feel discriminated against because of their low esteem and achievement (Ghazi, 2001). The dilemma is made worse when these two groups are asked to exchange ideas, leading to subjective peer reviews and growing hostilities. Without proper peer evaluation, learning within the context of a STAD group becomes stagnant (Lew, Mesch, Johnson \& Johnson, 1986). Based on the experiences of the writer, 
STAD can be futile when the lesson is not carefully customized and the teacher is not committed, leading to failure or superficial success (McCafferty, Jacobs \& Iddings, 2006).

Overall, despite the controversies towards the STAD practice, it is still selected among other derived variations because of its salience and importance as a CL instructional strategy (Felder \& Brent, 2001; Ghaith, 2001; Li \& Lam, 2005) ,owing to its simplicity and effectiveness, as well as the students' academic accomplishments, learning attitudes, socialization, and members' interdependence (Stevens, 2003). To advance our understanding of STAD, we discuss in the following section the different methodologies used in investigating the effectiveness of STAD, and how previous findings might inform a feasible field for future study.

\section{The Evaluation of the Methodologies and Their Implications}

Ghazi (2001) suggests that a study of STAD's efficacy is no longer vital given the apparent prevalence of previous studies; however, the difference in individuals and contextual factors may influence its implementation. Hence, Ghazi investigated students' enjoyment and reflection of STAD during an English lesson as Foreign Language (EFL) class. The study is unique because it examined the effect of gender and the students' achievement on their STAD experiences. Ghazi grounded the work on the Expectations States Theory, which states that the relative competence of group members is determined by the group's characteristics such as gender. Two instruments were utilized for the study. First, a domain-referenced pre-test examined their understanding of EFL rules and mechanics. The test's content validity was verified by the teachers, which consistently complies with other researchers' methodologies. The second instrument comprised a Likert-scale questionnaire on the students' perceptions of how much they have learned, what they have contributed to the learning of their groupmates, and whether they would suggest STAD for the class in the future. The two instruments effectively determined how much they could have acquired and what their opinions are with regard to the practice (Reason \& Bradbury, 2013). The marks obtained were used as improvement indicators. These improvement scores are fundamental to STAD study because they cumulatively identify the groups' overall learning attributes (Slavin, 1987). Using the improvement scores as indicators is a common investigative CL practice (Slavin, 1987).

However, it is doubtful that the sole use of questionnaires is effective in finding out the in-depth feeling of the respondents (Newmann \& Thompson, 1987). Within the restrictions of the quantitative approach, it is apparent that data could be possibly affected by the nature of the respondents, including their exposure and personality (Reason \& Bradbury, 2001). In a wider scope, neither might the respondents accurately express their deepest feeling in the sense that they tended to reflect socially desirable and favourable responses so that they would feel they were indifferent, nor were the misunderstanding towards the questions or slackness from respondents detected in questionnaires (Goodman, 1997). Another probability is that the standardized questions might potentially cause structural misconception, leading to that the data generated could only present the opinions of the researchers instead of the 
participants (Hannan, 2007). Some variables, such as the emotions and the feelings of the respondents, might also influence the outcomes of the questionnaires. For results analysis, the respondents could only interpret their own perceptions in terms of numerical scale rather than narrative so they might not have a chance to fully elaborate their feeling (Goodman, 1997).

From such perspective, it might be evident that quantitative research related to inquiry on a pedagogical innovation has demonstrated certain restrictions as a matter of fact that not every dimension towards a teaching method could be quantified (Burns, 2005). Addition of in-depth interviews might therefore remedy the weakness of the Ghazi's work because they are significant to receive detailed information related to feelings and views from individuals (Mishra \& Ramesh, 2013; Rabiee, 2004). Most importantly, ambiguities or misunderstanding can be immediately followed up or clarified, and they help the researchers to look into the statistical data. Conclusively speaking, interviews could arouse higher response rate and assure more in-depth questions as well as develop certain continuality of the inquiry (Bejarano, 1987)

Investigations on perceptions of pedagogy should be multi-faceted (Newmann \& Thompson, 1987; McCafferty, Jacobs \& Iddings, 2006). Teachers' perception and implementation is worth intensive study. In this regard Ghazi (2004) later surveyed 71 EFL teachers from various schools in Lebanon to triangulate teachers' experience and beliefs, their acceptance of STAD, and their perception of students' discipline. It is logically crucial to identify how the implementation of STAD relates to the teachers' beliefs on their transmission, interpretation, and attitudes, their perception of the strategy, and their own control of the lesson.

To build a consolidated and persuasive theoretical foundation, Ghazi adopted two theoretical frameworks. The first was Young and Lee's (1984) conceptualization of the transmission and interpretation models of instruction in a second language classroom. The second framework was based on Ajzen's Theory of Planned Behaviour (Felder \& Brent, 2001; Ghaith, 2001; Li $\&$ Lam, 2005). Three sets of questionnaires were applied. Five parts of the instrument are based on their transmissive and interpretive beliefs, teachers' perception of STAD learning behavior.

However, there were altogether 67 items in these five parts from the questionnaires, which could confuse and burden the participants and therefore downgrades the accuracy given that the amounts of items should be suitably adjusted (Goodman, 1997). Apart from the restrictions bounded by the use of the questionnaires, in order to fully comprehend how teachers' perceptions were related to their pedagogies, possibly there should be lesson observation and teachers reflection log books to clearly describe the teaching patterns in the classrooms (Lockhart, 1994). The major prominence of observation is that it avoids a variety of the problems associated with questionnaires or surveys, which are that the respondents are inclined to perform according to the sociably desirable norm and might not respond to the questionnaires accurately and completely. Observation therefore serves as a naturalistic and actual way to understand a classroom, especially the interaction between students and teachers, with which the data collected will be more reliable and accurate (Hattie, 2003). 
Moreover, observation can be implemented in various forms, ranging from informal to structured ones, and is highly compatible with both quantitative and qualitative researches. In short, it is highly applicable and practicable in a broad range of contexts (Lockhart, 1994; Hattie, 2003). The observation can also last longer depending on the actual need.

At root, in view of the appraisal and other school-based policies, the teachers may hesitate not to express their real opinions in the questionnaires or discussion. The use of questionnaires is perhaps effective in understanding partially the respondents' perception upon some issues (Hannan, 2007). However, it is crucially important to adopt other methods, such as observation, to retrieve deeper thoughts from the respondents.

Now, we ask whether the abovementioned literature effectively studied STAD. Seemingly quantitative researches are predominant in studying STAD so one may wonder how these kinds of researches might possibly be influenced by various contextual factors. Khan \& Inamullah (2011) in this aspect examined how STAD functioned in chemistry classes.

Khan \& Inamullah (2011) study used 30 twelfth graders in a government secondary school were as samples. Unlike Ghazi's works, some participants were placed into a control group instructed using the traditional teaching method while the experimental group was taught with Slavin's $(1980 ; 1987)$ STAD. The students in both groups were exposed to inorganic chemistry units for two weeks. For the experimental group that adopted STAD, the teaching content was covered in discussion and lectures where they were required to accomplish problem-solving tasks in pairs. Their progress and performance in learning was measured by the difference in their scores in various individual quizzes immediately marked after the completion of each unit.

It is intriguing that the measurement of the score difference may be effective in finding out how the students progressed in the experiment and control group (Kagan, 1995). However if the researcher questions are set to investigate the perception of participants towards how they learn in the classroom, apart from the interviews and observations which have been discussed before, the reflection from students are equally crucial. At root, the numerical data measured in the improvement scores could only assess the learning outcomes after the STAD instructional pedagogies but the progress was unexplored so the impacts brought by the STAD can hardly be comprehended, particularly in the perspectives of students. In this regard, the use of student learning log could perhaps remedy the above problem (Grundman, Schramm \& Reimer, 2003). First, learning logs can enhance the cohesion among the group members in the sense that they can always discuss on their learning logs. Second, it helps the researchers to look into their learning process so that how they perceive the new pedagogy and serves as the prism to deepen their understanding upon the numerical data. Most importantly, the respondents can seek advice from teachers and the teachers can always review their own teaching practice flexibly (Crooks, 1993)

Obviously, the ideas of using pretest and posttest as well as the improvement scores generated after the implementation should be placed central when we have to testify the effectiveness of a pedagogy but as aforementioned (Dimitrov \& Rumrill, 2003), they however should not merely be the one-size-fits-all methodologies but multi-faceted. 
Researchers based on students' and teachers' perception as well as the contextual factors influencing the STAD practice have been reviewed and evaluated. Now another question is if there are any studies attempted to modify the existing STAD instructional strategy on its five key components. Van Wyk (2012) further explored the effects of STAD by taking into account how achievement and attitude scores vary from the direct instructional method, and more in-depth, if STAD students were more accomplished, motivated, and nurtured with a modified STAD practice (Stevens, 2003).

In Van Wyk (2012) work, quasi-stratification, pre-test-post-test, and experimental/control groups were used. A total of 168 student teachers enrolled in elementary economics were invited to participate in the study. The experimental group was composed of 85 participants while the control group had 83 . Both groups were instructed by the same in which three instruments were deployed. Unlike the instruments used in previous studies, the questionnaires were conducted three times in forms of pre-, post, and post-post-test, and distributed before the practice, after the first round of practice, and after the second round of practice, respectively. The second instrument was the Test of Economic Literacy primarily reflected participants' subject knowledge on economic conceptualizations.

Van Wyk aimed to discern significant variations between the tests' means in the aspects of achievement, attitude, and learning motivation. Subsequently, independent and paired t-tests were implemented for the achievement and attitude tests between the two groups to identify any significant differences (Walter, 2009). The researcher cautiously maintained certain measures to ensure internal reliability and consistency as well as construct validity through independent and paired t-tests.

Compared with the quantitative researchers done by Ghazi (2001 \& 2004), Khan \& Inamullah (2011), Van Wyk adopted a circulative way to implement the questionnaires in three different periods - before the practice, during the practice and after the practice. Aforementioned it is undeniable that the predominant quantitative researches in some aspects are effective in looking into the respondents' perception but they do have limitations. To augment the frequencies of the questionnaires might perhaps help reassure the reliability of the data (Jollifie, 2007; Reason \& Bradbury, 2001). Technically speaking, augmentation data collection is achievable if the teaching practice is prolonged suitably.

Gillies (2004) investigated the difference in behaviors, interactions, and acquisition between the mathematics students in the structured and unstructured groups, and the variation in students' perception of STAD. Gillies' study involved 223 ninth graders in structured and unstructured groups during were stratified in groups of four based on mixed abilities. Among these six schools, three used STAD in their regular curriculum, so their structured grouping performed better during CL. The other three have not established any CL experiences.

Using an alternative method, the researcher adapted two observation schedules, which decoded the students' behavior and interaction. The observation first made by Sharan and Shachar (1988) and further developed by Gillies and Ashman (1996) The second observation instrument, which was originally designed by Webb (1985), was readapted by Gillies \& Ashman $(1996,1998)$ to analyze spoken interaction, A questionnaire on mathematics (highest 
possible score of 100) was also deployed. Bloom's Taxonomy (1956) was customized to justify task-solving activities. The final instrument, the "What Happened in the Groups Questionnaire" (WHGQ), was developed by Gillies and Ashman (1996) following the observation instrument on measuring positive interdependence.

Notably, in the methodology part, Gillies tried to manipulate the data triangulation by employing different techniques, namely, observation, questionnaires on teaching content, and questionnaires on student perception. Such measure constructed a more holistic understanding on STAD practice and prevented the research from being encapsulated in either quantitative or qualitative methodology (Walter, 2009; Reasons \& Bradbury, 2013). Yet Gillies' instruments are relatively inclined to be questionnaires. Additionally, the improvement of STAD measures remained unexplored for the primary focus remained on effectiveness instead of intervention. There might be potentially capacity for betterment if the triangulation of data also includes some focused group interviews and fulfilment of student learning $\log$ (Jolliffe, 2007; Walter, 2009; Reasons \& Bradbury, 2013). In short, the researches will be more comprehensive and reliable if there are more types of data collection which could complement each other. In consideration of such triangulation (observation, interview, questionnaire), a mixed approach, especially Action Research, a diagnostic methodology for research issues that remedies them with the data given, could perhaps be deployed more practically and feasibly when attempting to intervene in existing STAD practice (Jolliffe, 2007; Walter, 2009; Reasons \& Bradbury, 2013).

In view of the aforementioned evaluation of the methodologies, adoption of more than one method of data collection by means of triangulation - lesson observation, student learning log and pretest/posttest/ questionnaires could be highly practicable and pragmatic to maximize the quality of the evidence and its availability (Cohen, Brody \& Sapon-Shevin, 2004). These data should constitute a cooperative learning progress report which serves as the summative report to overview the students' perception upon the STAD practice so that the researcher can address the respondents' concern

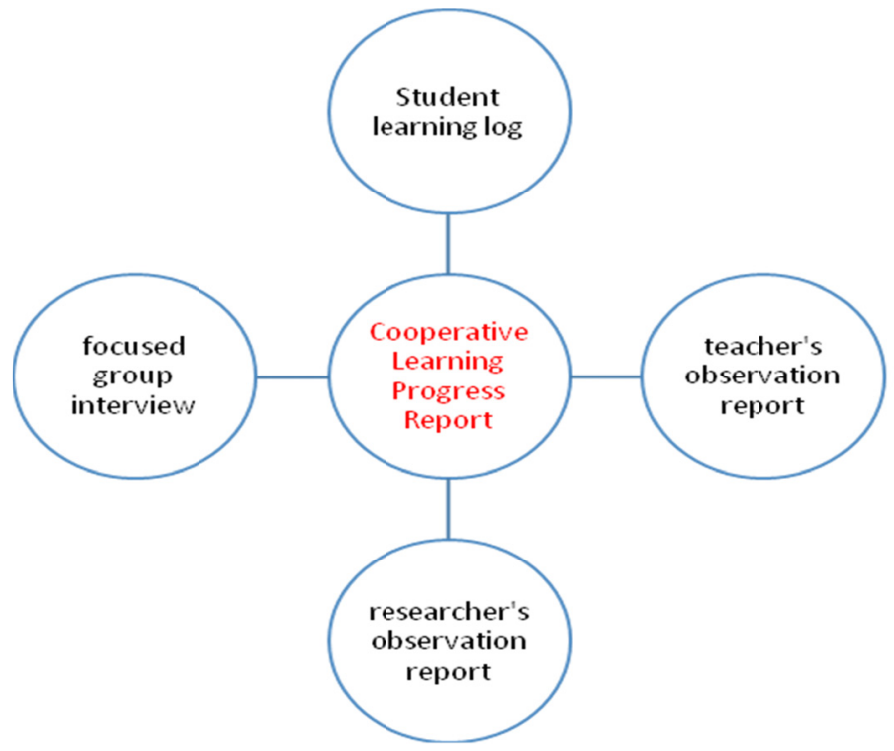

Figure 1. Students' feedback, researcher's reflections, and colleagues' lesson observation report as a reflection of the intervention 


\section{The Implications of the Research Findings}

The results of Ghazi's (2001) study are significant. They show that most students approve of STAD owing to its usefulness, enjoyable quality, worthiness, and clarity. Thus, this strategy is highly recommendable. Ghazi's work successfully proved that most students opt for STAD regardless of their gender and previous attainment. Nonetheless, the results similarly reveal that though male students are relatively more adept to various aspects and the operation skills and procedures of STAD, 31\% were reluctant to recommend its adoption as a teaching strategy.

To sum, apart from the influence of socialization on the learners' experience, the extent by which the interaction between low and high achievers contributes to STAD dynamics is another topic that requires further investigation. In addition, how the above variables are related to the school culture and its linguistic contexts is also worth exploring. Ghazi (2001) provides a rough picture of how students with varying gender and achievements perceive STAD strategies. However, Ghazi was unable to concretely investigate the prominence of STAD in the perspective of socialization. Instead, we can further intervene based on the notion that a mixed group's social cohesion influences the effectiveness of STAD strategies (Slavin, 1987).

Ghazi (2004) work on teachers whereas are controversial. The study found that teachers aligned with the interpretive model, whether or not they considered themselves as facilitators of students' learning, are more likely to adopt STAD than teachers who believe themselves to be transmitters. Such finding is insightful for it reinforces the teaching rationale and ideologies are responsible for the survival of instructional innovations (Ghaith, 2003). Second, the results show that stakeholders' attitudes toward STAD affect its implementation. Teachers are more likely to implement innovative instructional methods if they receive more consent and recognition from parents, students, and school administrators. Ghazi clearly demonstrated a range of factors, including resources, curriculum, administrative support, and adoption of small classes, may influence teachers' implementation of STAD (Gillies, 2004). No differences were observed between experienced and new teachers as regards their willingness to implement STAD. Such willingness is subject to their reception to instructional innovations (Johnson, Johnson \& Stanne, 2000).

However, there is still inadequacy in Ghazi's work that the teachers' motivation to implement STAD remains ambiguous because of the restrictions of quantitative research as aforementioned (Ghazi, 2004). Affirmatively, knowing how students and teachers interact mutually in STAD is noteworthy (Felder \& Brent, 2001). A researcher can discover the dynamics between the school, students, and teachers if he actively engages himself in the teaching role. Hence, another question raised in this area is whether the researcher is eligible, as a teacher, to clarify how teacher perceptions relate to students' knowledge acquisition.

Looking at the results from Khan and Inamullah (2011), the experimental group performed slightly better compared with the control group, but intriguingly their achievements were indifferent (Khan \& Inamullah, 2011). Similar results were obtained in another research on home economics students by Rosini, Jim and Fakultai (1994). Khan \& Inamullah quoted 
Slavin's work, that $37 \%$ of students from 70 relevant studies reported no difference in their achievements regardless of STAD implementation. Khan \& Inamullah proposed three possible reasons for such phenomenon. The first was the absence of the pre-test, which could have served as the base for the contrast. The second was the restraint on time allocation and environment, 15 minutes in each STAD session and very limited space for open discussion. The last reason was the small size of the sample and the very specific context. Khan \& Inamullah suggested that using a mixed methodology to address such limitations. We can deduce that Khan \& Inamullah affirmatively established an important prerequisite for the successful practice of STAD research - time allocation, environment, sampling size, and the use of instruments, which are significantly important to what might determine the methodologies for the study on STAD. As aforementioned, sole quantitative research on STAD perception is still inadequate.

The result of Van Wyk underscored STAD as consistently regarded as the most congruent CL strategy in refining academic accomplishments (Liang \& Mohan, 2003). Congruent with previous studies, accomplishments were markedly augmented when STAD was properly operationalized (Armstrong \& Palmer, 1998; Kagan, 1995)

In order to assure the sustainability of the work, Van Wyk (2010) attempted to deploy another quasi-experimental practice with pre-test and post-test tools measuring students' progress in another economics class. A significant improvement was reflected upon the higher increase of marks from pre-test to post-test when compared with the control group. Van Wyk's longitudinal study prolonged the implementation to two periods, leading to a more stable and apparent increment in scores. Through the repeated reinforcement of the STAD elements, it is apparently prevalent that STAD can be cultivated and revised developmentally and sustainably (Burns, 2005). Appropriate interventions show that STAD can be maximized to benefit student learning. Thus, it is feasible to have certain diagnostic looping. PAR might hence be deployed.

Gillies (2004) significantly result showed that students in structured groups are more willing to listen, ask for elaborations, share ideas, and provide assistance. Therefore, we can conclude that effective learning exists when it is affiliated with prompt assistance, which has to be precise, detailed, and appropriate to the recipients' needs (Bejarano, 1987). Controversially, STAD is not equivalent to proper and cohesive implementation because teachers are very likely to be resistant to instructional innovations and mediate STAD based on their own teaching rationale or convenience (Stevens, 2003). Thus, STAD strategies in unstructured settings fail to produce desired outcomes (Ghaith, 2003; Ghaith, 2004). As mentioned before, one of the key questions is how teachers can be motivated to adopt STAD. Ghazi's work shows that teachers' experience is not related to their willingness to implement STAD, but their teaching rationale is. If a researcher assumes the role of a tutor, motivational experiences may perhaps be more accessible (Haller, Gallagher, Weldon \& Felder, 2000). 


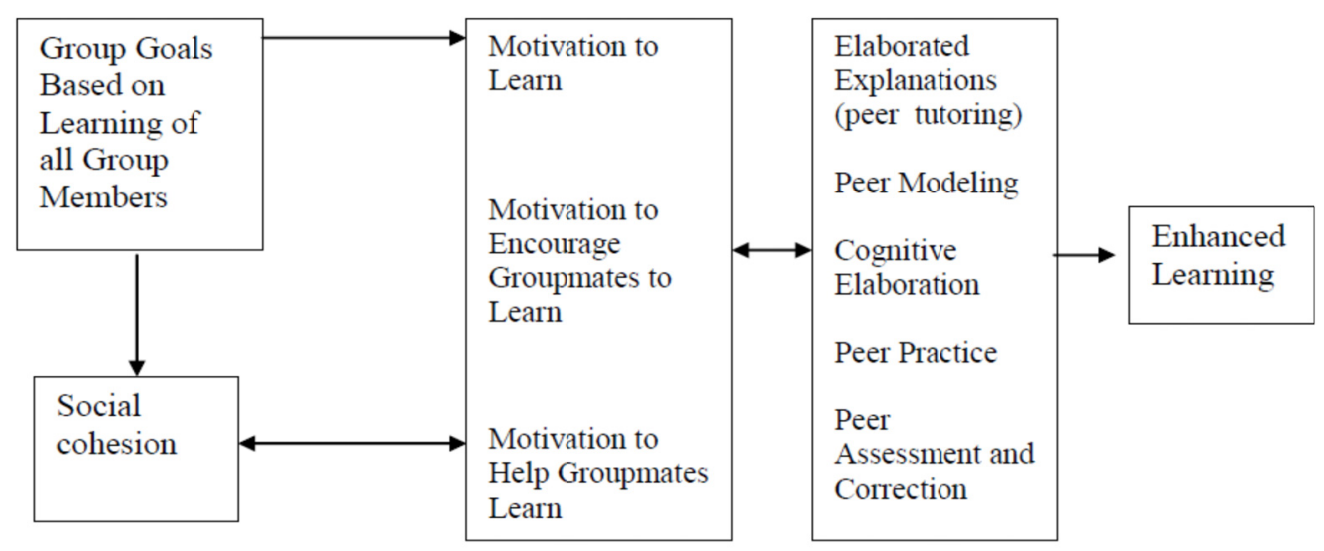

Figure 2. Integration of theoretical perspectives on effects of cooperative learning on learning (adapted from Slavin, R. (2011). Cooperative learning. Learning and Cognition in Education)

\section{The Feasibility of Adopting Participative Action Research(PAR)}

As suggested in the evaluation of the methodologies and finding parts, we can tentatively establish the topic as "A participatory action research adopting STAD in a Hong Kong local elite secondary school," with the following research questions. First, what are the effects of intervention on second language learners in the context of a STAD learning group? Second, what are the restrictions of STAD on second language students?

In the preceding section, PAR has been proposed to study how STAD can be further improved. As a derivation of qualitative research, PAR is developed based on constructivism (Burns, 2005). It embodies an interpretative, participative, explorative, and naturalistic nature by first exploring participants' perception of the research topic and their acts to clarify the topic (Crooks, 1993). The researcher, as the facilitator, will customize action plans for educational purposes. Most crucially, the researcher will evaluate his teaching based on the feedback from the questionnaire, interviews, self-learning log, observations, and other instruments. These data serve as the foundation for the improvement of existing practice. The procedure will be conducted repeatedly until the solutions are determined. In other words, the process involves planning, action, observation, and reflection. The researcher will also have to consider classroom discipline, materials development, teaching content, and time constraints (Burns, 2005). PAR is widely deployed in assessing interventional measures on existing practices in organizations such as universities, firms, communities, and schools, on the rationale that teacher-centered approach should be refrained (Reasons \& Bradbury, 2001)

We observe the appropriateness of the deployment of PAR to study how to further improve STAD. First, many studies have concluded that STAD is beneficial and salient in regard its theory and research-based conceptualization. Nevertheless, only a few studies provided recommendations on how STAD can be improved; PAR could address this gap in view of its diagnostic characteristic (Walter, 2009). Second, both quantitative and qualitative approaches are usually inadequate to investigate different aspects of an instruction strategy, a study that 
should be multi-faceted. The PAR approach is a mixed methodology that is commonly adopted. Hence, PAR is potentially practical, holistic, and achievable. Third, the influence of various variables on STAD practice remains ambiguous and unclear, such as school socialization and knowledge acquisition in the STAD context, the interaction between high and low achievers, and the motivation of teachers, while PAR will be more inclusive to look into these variables. Furthermore, PAR provides researchers with more flexibility to modify action plans at different intervals during implementation. Hence, researchers can always retrace the unsettled problems for alternative solutions (Reasons \& Bradbury, 2013).

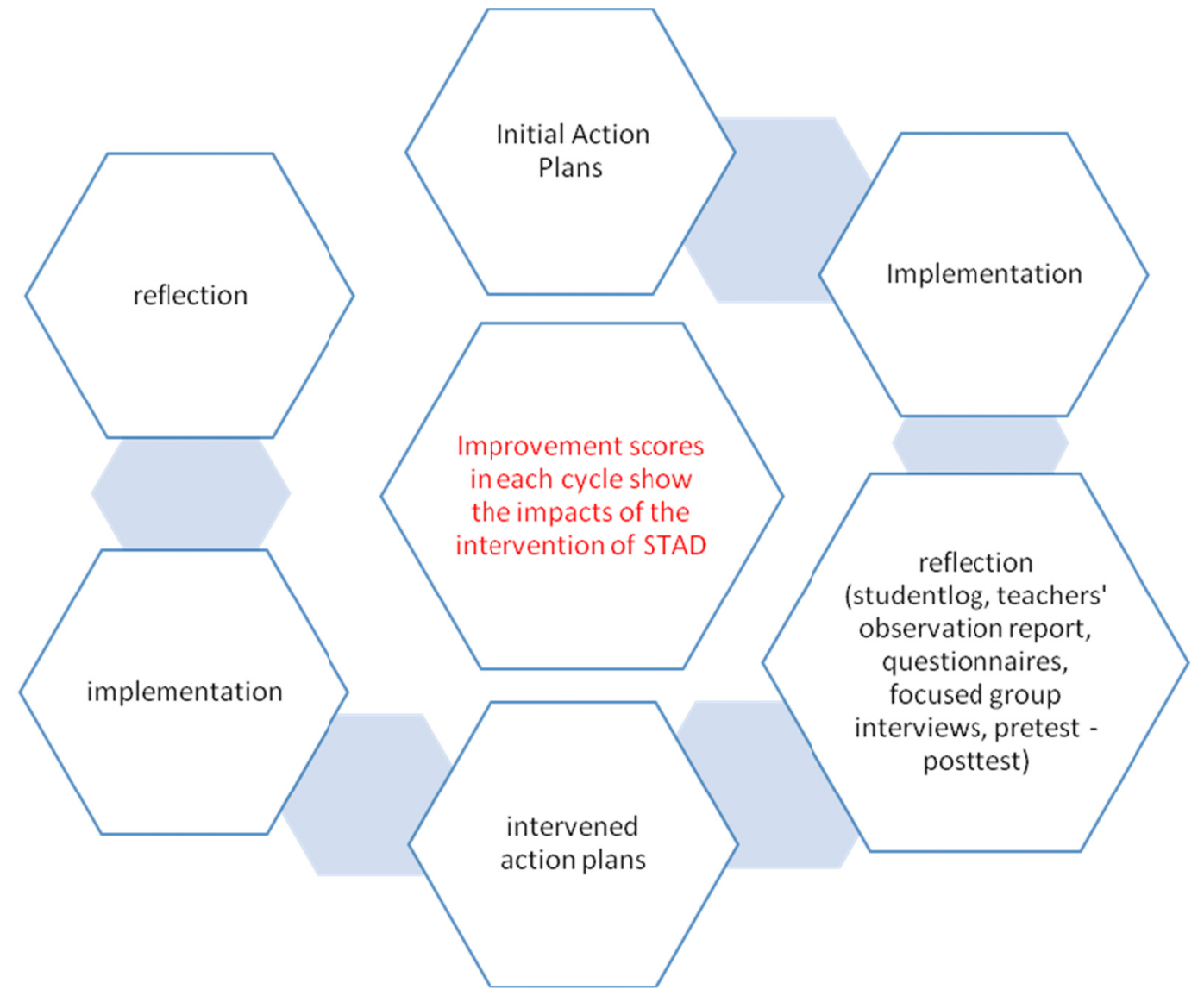

Figure 3. The cycle showing the implementation of the PAR for STAD

\section{Conclusion}

As aforementioned, various investigations have examined the effectiveness of STAD using questionnaires for teachers and students, based on their perceptions toward such CL variance. However, these studies rarely review the possible interventions for the improvement of existing STAD practice in Hong Kong local secondary schools; its effectiveness has not yet been proven. Thus, we can tentatively establish the topic as "A participatory action research adopting STAD in a Hong Kong local elite secondary school," with the following research questions. First, what are the effects of intervention on second language learners in the context of a STAD learning group? Second, what are the restrictions of STAD on second language students? 


\section{References}

Ajzen, I. (2011). Theory of planned behavior. Handb Theor Soc Psychol Vol One, 1, 438.

Armstrong, S., \& Palmer, J. (1998). Student Teams Achievement Divisions (STAD) in a twelfth grade classroom: Effect on student achievement and attitude. Journal of Social Studies Research, 22, 3-6.

Bejarano, Y. (1987). A Cooperative Small - Group Methodology in the Language Classroom. TESOL Quarterly, 21(3), 483-504. http://dx.doi.org/10.2307/3586499

Burns, A. (2005). Action research: An evolving paradigm? Language Teaching, 38(2), 57-74. http://dx.doi.org/10.1017/S0261444805002661

Cohen, E. G., Brody, C. M., \& Sapon-Shevin, M. (2004). Teaching cooperative learning: The challenge for teacher education: Suny Press.

Crookes, G. (1993). Action research for second language teachers: Going beyond teacher research. Applied Linguistics, 14(2), 130-144. http://dx.doi.org/10.1093/applin/14.2.130

Dimitrov, D. M., \& Rumrill, J., Phillip D. (2003). Pretest-posttest designs and measurement of change. Work: A Journal of Prevention, Assessment and Rehabilitation, 20(2), 159-165.

Felder, R. M., \& Brent, R. (2001). Effective strategies for cooperative learning. Journal of Cooperation \& Collaboration in College Teaching, 10(2), 69-75.

Ghaith, G. (2001). Learners' perceptions of their STAD cooperative experience. System, 29(2), 289-301. http://dx.doi.org/10.1016/S0346-251X(01)00016-1

Ghaith, G. (2002). The relationship between cooperative learning, perception of social support, and academic achievement. System, 30(3), 263-273. http://dx.doi.org/10.1016/S0346-251X(02)00014-3

Ghaith, G. (2003). Effects of the learning together model of cooperative learning on English as a foreign language reading achievement, academic self-esteem, and feelings of school alienation. Bilingual Research Journal, 27(3), 451-474. http://dx.doi.org/10.1080/15235882.2003.10162603

Ghaith, G. (2004). Correlates of the implementation of the STAD cooperative learning method in the English as a foreign language classroom. International Journal of Bilingual Education and Bilingualism, 7(4), 279-294. http://dx.doi.org/10.1080/13670050408667813

Ghaith, G. M. (2003). Relationship between reading attitudes, achievement, and learners perceptions of their Jigsaw II cooperative learning experience. Reading Psychology, 24(2), 121. http://dx.doi.org/10.1080/02702710390197444

Gillies, R. M. (2003). Structuring cooperative group work in classrooms. International $\begin{array}{llll}\text { Journal of } & \text { Educational 35-49. }\end{array}$ http://dx.doi.org/10.1016/S0883-0355(03)00072-7 
Gillies, R. M. (2004). The effects of cooperative learning on junior high school students during small group learning. Learning and instruction, 14(2), 197-213. http://dx.doi.org/10.1016/S0959-4752(03)00068-9

Goodman, R. (1997). The Strengths and Difficulties Questionnaire: a research note. Journal of child psychology and psychiatry, 38(5), 581-586. http://dx.doi.org/10.1111/j.1469-7610.1997.tb01545.x

Haller, C. R., Gallagher, V. J., Weldon, T. L., \& Felder, R. M. (2000). Dynamics of peer education in cooperative learning workgroups. Journal of Engineering Education, 89(3), 285-293. http://dx.doi.org/10.1002/j.2168-9830.2000.tb00527.x

Hannan, A. (2007). Questionnaires in education research. University of Plymouth Retrieved from http://www.edu.plymouth.ac.uk/resined/QUESTS/index.htm

Hattie, J. (2003). Teachers make a difference: what is the research evidence? : Australian Council for Educational Research Camberwell.

Hertz-Lazarowitz, R., \& Miller, N. (1995). Interaction in cooperative groups: The theoretical anatomy of group learning: Cambridge University Press.

Jacob, E., Rottenberg, L., Patrick, S., \& Wheeler, E. (1996). Cooperative Learning: Context and Opportunities for Acquiring Academic English*. TESOL Quarterly, 30(2), 253-280.

Johnson, D. W., \& Johnson, R. T. (2009). An educational psychology success story: Social interdependence theory and cooperative learning. Educational researcher, 38(5), 365-379. http://dx.doi.org/10.3102/0013189X09339057

Johnson, D. W., Johnson, R. T., \& Skon, L. (1979). Student achievement on different types of tasks under cooperative, competitive, and individualistic conditions. Contemporary Educational Psychology, 4(2), 99-106. http://dx.doi.org/10.1016/0361-476X(79)90063-8

Johnson, D. W., Johnson, R. T., \& Stanne, M. B. (2000). Cooperative learning methods: A meta-analysis.

Jolliffe, W. (2007). Cooperative learning in the classroom: Putting it into practice: Sage.

Kagan, S. (1995). We Can Talk: Cooperative Learning in the Elementary ESL Classroom. ERIC Digest.

Khan, G. N., \& Inamullah, H. M. (2011). Effect of Student's Team Achievement Division (STAD) on Academic Achievement of Students. Asian Social Science, 7(12), 211. http://dx.doi.org/10.5539/ass.v7n12p211

Lew, M., Mesch, D., Johnson, D. W., \& Johnson, R. (1986). Components of cooperative learning: Effects of collaborative skills and academic group contingencies on achievement and mainstreaming. Contemporary Educational Psychology, 11(3), 229-239. http://dx.doi.org/10.1016/0361-476X(86)90019-6

Li, M., \& Lam, B. (2005). Cooperative learning.

Liang, X., \& Mohan, B. A. (2003). Dilemmas of cooperative learning and academic 
proficiency in two languages. Journal of English for Academic Purposes, 2(1), 35-51. http://dx.doi.org/10.1016/S1475-1585(02)00032-2

Lockhart, C. (1994). Reflective teaching in second language classrooms: Cambridge University Press.

McCafferty, S. G., Jacobs, G. M., \& Iddings, A. C. D. (2006). Cooperative learning and second language teaching: Cambridge University Press.

Mishra, S., \& Ramesh, R. (2013). A Software Solution to Facilitate Moderation, Observation and Analysis in a Focused Group Interview (FGI). Paper presented at the Technology for Education (T4E), 2013 IEEE Fifth International Conference on.

Newmann, F. M., \& Thompson, J. A. (1987). Effects of Cooperative Learning on Achievement in Secondary Schools: A Summary of Research.

Rabiee, F. (2004). Focus-group interview and data analysis. Proceedings of the nutrition society, 63(04), 655-660. http://dx.doi.org/10.1079/PNS2004399

Reason, P., \& Bradbury, H. (2001). Handbook of action research: Participative inquiry and practice: Sage.

Reason, P., \& Bradbury, H. (2013). The SAGE handbook of action research: Participative inquiry and practice: Sage.

Slavin, R. E. (1980). Cooperative learning. Review of educational research, 50(2), 315-342. http://dx.doi.org/10.3102/00346543050002315

Slavin, R. E. (1987). Cooperative learning: Student teams. What research says to the teacher: ERIC.

Slavin, R. (2011). Cooperative learning. Learning and Cognition in Education Elsevier Academic Press, Boston, 160-166.

Stevens, R. J. (2003). Student team reading and writing: A cooperative learning approach to middle school literacy instruction. Educational Research and Evaluation, 9(2), 137-160. http://dx.doi.org/10.1076/edre.9.2.137.14212

Van Wyk, M. M. (2012). The Effects of the STAD-Cooperative Learning Method on Student Achievement, Attitude and Motivation in Economics Education. J Soc Sci, 33(2), 261-270.

Walter, M. (2009). Participatory action research. Social research methods, 2, 1-8.

\section{Copyright Disclaimer}

Copyright for this article is retained by the author(s), with first publication rights granted to the journal.

This is an open-access article distributed under the terms and conditions of the Creative Commons Attribution license (http://creativecommons.org/licenses/by/3.0/). 